\title{
Application of Management and Control Techniques in Brazilian Construction Industry
}

\author{
Núbia Gremion $^{1}$, Fernando Figueiredo ${ }^{1}$, Elaine Vazquez ${ }^{2}$ and Lais Alves ${ }^{3 *}$ \\ ${ }^{1}$ Department of Planning and Management Research (NPPG)- Federal University of Rio de Janeiro (UFRJ), Rio de Janeiro, Brazil \\ ${ }^{2}$ Department of Civil Construction - Federal University of Rio de Janeiro (UFRJ), Rio de Janeiro, Brazil \\ ${ }^{3}$ Departmanent of Mechanical Engineering, Federal Center for Technological Education Celso Suckow da Fonseca (CEFET? RJ), Rio de Janeiro, Brazil
}

*Corresponding author: Lais Alves, Federal Center for Technological Education Celso

Suckow da Fonseca (CEFET/RJ), Brazil.

Received Date: May 15, 2019

Published Date: May 22, 2019

\begin{abstract}
The planning process is imperative for the construction industry as a management tool for building and residential construction firms. Effective planning procedures coordinate, monitor and guide processes for enhanced outcomes. Unfortunately, inadequate planning or no coherent outlining is the reality for most Brazilian companies in the construction sector, i.e. the Architecture, Engineering and Construction (AEC) sector. This article aims to review a set of practical models for better planning and controlling for vertical building construction focusing on currently available software in the local market. By examining these techniques this article also intends to disseminate awareness regarding current concerns in the industry.
\end{abstract}

\section{Introduction}

The planning process is just as relevant for organizations as the production process itself. Planning encourages collaborators to think about hurdles and opportunities by using past events as building blocks to respond to what is happening now and predict what will happen next. A good and practical plan is the manifestation of a company that is prepared to endure and thrive in many conditions. The word planning expresses the action or act of planning, creating a plan to achieving a given goal. This word encompasses multiple fields. Planning is an important competency of management and administration, which is related to the preparation, organization, and structuring of a given goal. It is essential in the decision-making process and in performing those same tasks. An individual who uses planning as a tool in his work demonstrates an interest in prognosticating and coordinating actions that will happen in the future, increasing their rationality and effectiveness [1].

Chiavenato [2] identifies the planning process as a permanent and continuous process, i.e. the function of planning is carried out at all times in the organization, and it is necessary to be planning the activities throughout the business process. Planning aims to anticipate actions that will potentially occur in a future moment since current events no longer need planning. During construction, foreseeing possible outcomes is vital. Planning allows teams to set specific actions for each molded scenario. Thus, contingency plans should consider changes in environment variables. The planning should include essential information on all activities that will be performed during construction, e.g. labor costs fluctuations; stocks management; equipment deterioration; delivery time; and so on. All data must be available for qualified personnel responsible for oversight. Delays may be caused by insufficient labor force or errors in the supply chain. Therefore, it is important to work with a proper schedule to anticipate well-known issues [3]. Planning provides strategies to achieve what is proposed, and there are so many types that it is up to the company to determine what is suitable for each application. Defining which objectives are required in a determined time frame is fundamental for strategic framework conception. Strategic planning establishes priorities and resources to move towards an agreeable goal that encapsulates values shared by stakeholders. According to Fayol [4], there is also an operational planning function. This role goes beyond specific technical knowledge. This managerial function requires a diversified skill set which encompasses interpersonal relationships, learning strategies and teamwork. Planning and control are essential to run an effective and efficient logistics operation. Dias [5] states that planning should be undertaken according to a planning time 
horizon, a certain kind of hierarchy generally classified as strategic, tactical and operational. These three management tools work on different levels at the same time that underline the need for appropriate planning and control as shown in the image below (Figure 1).

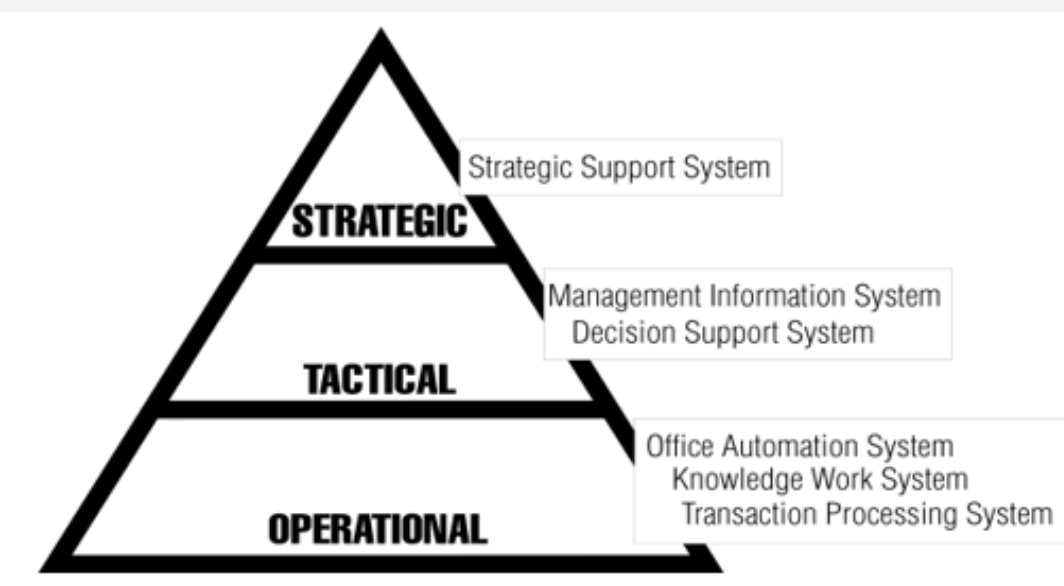

Figure 1: Strategic, Tactical and Operational Management Relationship.

Operational planning is associated with efficiency. According to Fayol [4] the advantages of good planning are greater flexibility; promptness in decision making; enhanced communication between peers; improved top-to-bottom managerial discipline; enhanced orientation in employee behavior; enhanced employee ability and qualification through motivation and commitment of those involved. By improving the environmental awareness in which employees operate, though an attuned understanding of the company's values and mission, it is possible to increase capability and adaptation speed. To reach long-term goals, a company needs to delineate a path to achieve these objectives. Only by distilling critical factors, internal and external, therefore generating plans of action through scenario building, proper communicating it to interested parties and finally evaluating short-term outcomes it is possible to reach these deliberate goals. Since strategic management favors long-term objectives, some disadvantages should be addressed. Developing and communicating a strategy requires a great deal of time and focus, reducing high-end employee productivity. Skillful planning is pristine and reduces the risk considerably, but it also needs to be learned and used by the whole corporation. Like other activities, strategic management has a learning curve and may be hard to implement it at the beginning. Construction projects can be onerous endeavors. Project's success is often dependent on creating and adhering to a sound budget. By proper research, it is possible to run a multivariable analysis cataloging and forecasting hard, soft, land and unforeseen costs. A systematic budget building with some degree of flexibility avoids omissions, errors, delays and even incompletion. According to Dias [6], budget projection predicts expenditures in services, construction supplies, and required equipment. Kotler Philip [7] states that budgeting varies with each type of project. Some may require more equipment and others are labor intensive. But adhering to a single model might be disastrous. Clear scope; familiarization with the selected template; understanding which item variables are; accounting for hidden costs and aggregated risks; and flexibility are keys to successful budgeting.

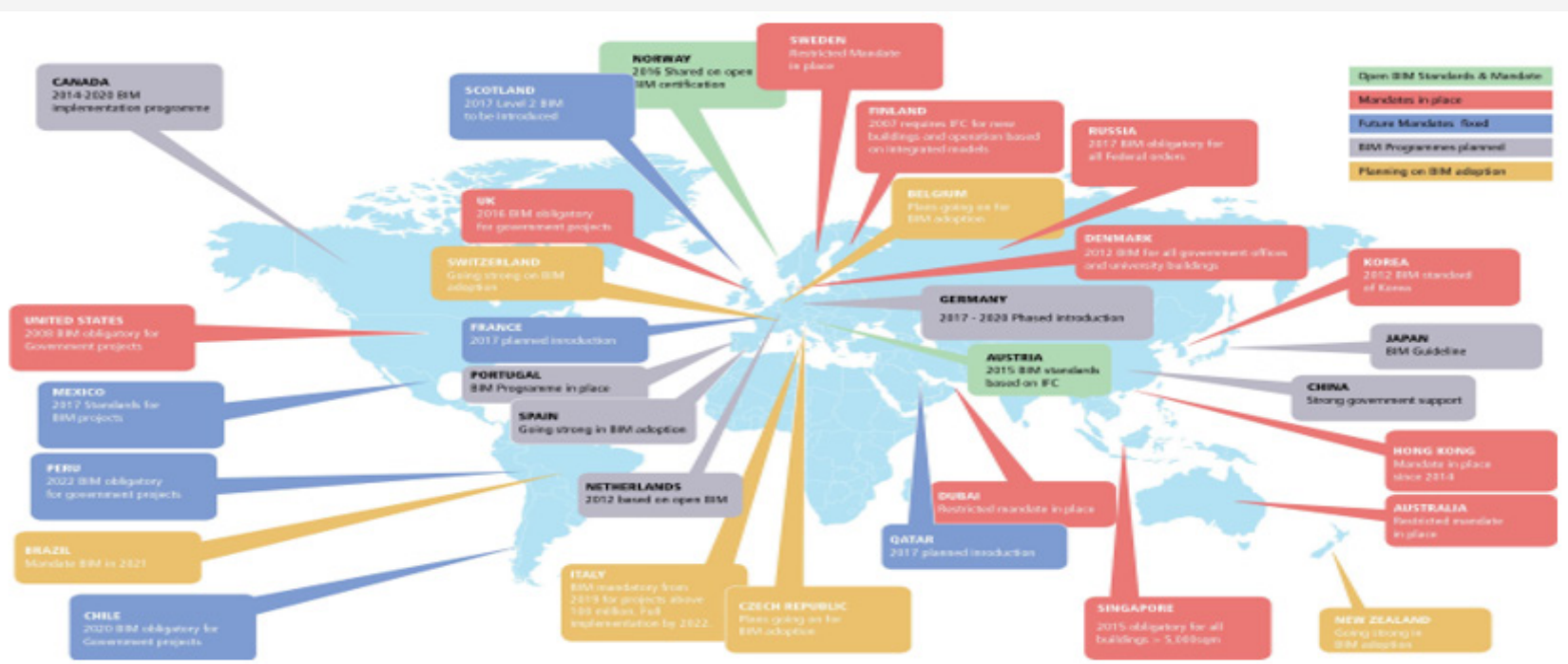

Figure 2: Global BIM Regulation Evolution. In: https://www.geospatialworld.net/article/bim-adoption-around-the-world-how-good-are-we/ 
The network approach to planning and scheduling consists of methods focus on calculating or critical path optimizing between the elements. Formoso [8] identifies the balance sheet line, the Critical Path Method (CPM) and the Program Evaluation Review Technique (PERT). Typically, these two lasts concepts are so complementary that are called PERT/CPM. While there are some Project Planning, Estimating, Contingency Planning Programmes (PPCP) that use those means, since the advancement of information technology, new tools have arisen all over the world, like BIM. The Building Information Modeling (BIM) technology is the highlighted and most promising development in the AEC industry, a powerful multifunction resource that encourages the integration of the roles of all stakeholders, as well as their collaboration on a project. The traditional construction process, from concept design to final construction, implies generating multi-stage drawings and specifications to contractors. Once it generates and manages data of built assets, a BIM software can transform the whole process, producing coordinated sets of information. It can be used not just for design, construction, and operation of the facility, but also for planning (e.g. the built-in cost estimating features: on their behalf, a BIM software can extract and update material quantities automatically). There is a world acceptable criteria of BIM maturity, from Level 0-3: in its simplest form it means no collaboration, while the most complex one - not yet fully defined -, looks forward to establishing a new contractual framework for projects which have been procured with BIM to ensure consistency, avoid confusion and encourage open and collaborative working. BIM had become mandatory in the United Kingdom in 2011. Meanwhile, the UK instituted the most striving and radical BIM strategy in the world. If a company is not BIM Level 2 complaint, this firm cannot apply to any British government project. The adoption of BIM processes has risen recently worldwide as the construction industry becomes largely aware of its benefits (Figure 2).

Following a BIM roadmap, a Strategic Committee for the Implementation of BIM (CE-BIM) and a Technical Support Group (CAT-BIM) were established in Brazil in 2017 to draw rules that could mandate BIM in 2021. The local reality, however, is not prepared to reach the British level, but the initiative is a great first practical step towards the establishment of BIM processes. Despite studies conducted in 2013, the majority of the local construction industry has no BIM experience, and it could be explained by a cultural indicator: people do not commit themselves to simple planning routine tasks, despite the entrepreneur country profile (according to SEBRAE, 3-10 Brazilians are involved with their own business). This lack of planning is a reoccurring hassle and, therefore, might explain the constant causes of delays in its construction industry, as the absence of a well-structured schedule and, mainly, a well-defined budget. If the entrepreneurs still do not believe in the importance of a good planning, how could Brazil stand out in the BIM world scenario? Individuals that erroneously manage their careers and finances. make their own organizations suffer from mismanagement of people, products and services. Therefore, planning is the best way to visualize the desired state, get out of the current state and stimulate development [9]. Without proper planning is practically impossible for a company or a project manager to reach any degree of confidence that future objectives will be met in a determined time frame. Often, an unorganized project will eventually lead to expensive reworks or even incompletion, heavily penalizing investors and stakeholders. For solid planning some factors should be considered: Scenario building, raising awareness about contingencies, risks, and limitations which may be confronted in the future. SWOT analysis, or any other suitable ambient analysis, evaluating the company's competitive position, developing a strategic plan tailored for the project or company needs; Strategic control systems, controlling the formation and execution of strategic plans. emphasizes that planning is irrelevant when managers do not track results or continuously reconcile it. Thus, Planning requires a revolutionary attitude as much as it requires previsibility to achieve desirable results (Figure 3 ).

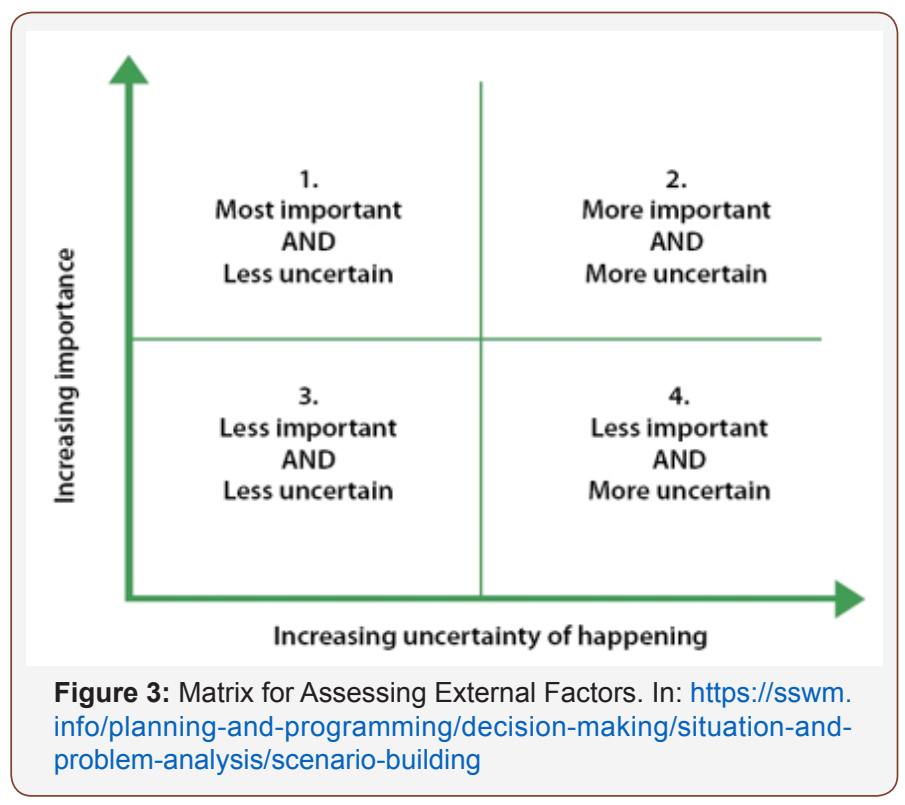

\section{Discussion}

A company must define its target market, i.e. the portion of the consumers it intends to aim. In association with the positioning process, i.e. the targeting process, companies theoretically utilize some process to define its marketing mix. This process is key to visualize the company's relative position within its industry. A variable that directly affects profitability as depicted by Porter's Generic Competitive Strategies. Strategic alignment is key to remove overlaps and increase profits [10]. A production process is designed to overcome potential supply shortages during the production process. Overcoming possible idleness of both equipment and human capital is also essential. Safety and maintenance are also mattering of great importance in the production process. Reliable and maintained machinery is likely to maximize its utility causing no delays in production. The workload, as previously mentioned, is also a concern in the process. It should be well-balanced avoiding idleness or anxiety. Modern software developers provide a more systematic approach by applying complex statistics and matrixes with a multi-variable array of solutions. Currently, two big software 
developers dominate the market: MS Project by Microsoft and Primavera by Oracle. Both systems provide settings to control costs, workloads, and schedules in adjustable levels of complexity. Of all the project management software, as previously mentioned, MS Project is one of the most adopted today by project managers and AEC professionals. With this application is possible to schematize and manipulate all the activities of a project. Labor cost, scheduling, supply chain and so on. Contrarily to standardized spreadsheet software, using tailor-made applications like MS Project employs less manpower and yet generates better solutions in a simplified environment. Microsoft Project is affordable in comparison with Primavera by a fair amount. In contrast, Primavera is considerably more robust, an essential feature for more complex enterprises. Primavera Contract Manager enables users to manage each step of a project with ease. Nevertheless, there are some limitations. Although Primavera is a noticeable tool, the application is known to be vulnerable to network problems when more than one user is feeding data for a project; Historical data is not accessible; The amount of fonts and colors available is restricted; Primavera currently does not provide a Portuguese version. On the other hand, advantages and ingenuities are also worthy mentionings. The concept of activity code; logical manipulation of data; Multi collection of cost centers; and navigation by critical line, with the dominance relationship are good examples.

\begin{tabular}{|c|c|c|c|c|c|}
\hline \multicolumn{6}{|c|}{ SOFTWARES COMPARING COSTS TABLE } \\
\hline \multirow[b]{2}{*}{ Company } & \multicolumn{2}{|c|}{ MS PROJECT } & \multicolumn{3}{|c|}{ PRIMAVERA P6 } \\
\hline & \multicolumn{2}{|c|}{ Microsoft } & \multicolumn{3}{|c|}{ Oracle } \\
\hline \multicolumn{6}{|c|}{ SOFTWARE'S INFORMATIONS } \\
\hline Software \& license costs & \multicolumn{2}{|c|}{$\mathrm{R} \$ 130,00$} & \multicolumn{3}{|c|}{$\mathrm{R} \$ 10.204,00$} \\
\hline licence's period of validity & \multicolumn{2}{|l|}{ monthly } & \multicolumn{3}{|c|}{ perpetual licence } \\
\hline \multicolumn{6}{|c|}{ COURSES' INFORMATIONS } \\
\hline $\begin{array}{r}\text { face-to-face trainning } \\
\text { software course }{ }^{1}\end{array}$ & R\$ 668,10 $\begin{array}{c}\text { (16 hours/ } \\
\text { course) }\end{array}$ & or $12 \times \mathrm{R} \$ 69,08$ & $\mathrm{R} \$ 602,70$ & $\begin{array}{l}\text { (16 hours/ } \\
\text { course) }\end{array}$ & or $12 \times \mathrm{R} \$ 60,51$ \\
\hline $\begin{array}{r}\text { online trainning software } \\
\text { course }\end{array}$ & $\mathrm{R} \$ 658,61 \quad \begin{array}{c}\text { (16 hours/ } \\
\text { course) }\end{array}$ & or $12 \times \mathrm{R} \$ 66,12$ & R\$ 576,87 & $\begin{array}{l}\text { (16 hours/ } \\
\text { course) }\end{array}$ & or $12 \times \mathrm{R} \$ 57,92$ \\
\hline $\begin{array}{r}\text { face-to-face trainning } \\
\text { advantage and basic } \\
\text { software course }{ }^{2}\end{array}$ & $\mathrm{R} \$ 759,00 \quad \begin{array}{c}(24 \text { hours/ } \\
\text { course })\end{array}$ & or $2 \times \mathrm{R} \$ 389,00$ & - & & - \\
\hline $\begin{array}{r}\text { face-to-face trainning basic } \\
\text { software course } \\
\end{array}$ & - & - & R\$ 415,00 & $\begin{array}{l}\text { (12 hours/ } \\
\text { course) }\end{array}$ & - \\
\hline $\begin{array}{l}\text { online learning plataform } \\
\text { software full course }\end{array}$ & $\begin{array}{c}\text { R\$309,99 } \begin{array}{c}(5,5 \text { hours/ } \\
\text { course })\end{array}\end{array}$ & $\begin{array}{c}\mathrm{R} \$ 23,99 \text { (special } \\
\text { prico) }\end{array}$ & $R \$ 549,99$ & $\begin{array}{l}\text { (3,5 hours/ } \\
\text { course) }\end{array}$ & $\begin{array}{c}\mathrm{R} \$ 23,99 \text { (special } \\
\text { prico) }\end{array}$ \\
\hline
\end{tabular}

'Trainning Education Center, São Paulo

${ }^{2}$ Bramante Institute, Rio de Janeiro

3Project Management Knowledge Base Trainning Center (PMKB), Belo Horizonte

Figure 4: Softwares Comparing Costs Table.

Microsoft Project is a successful proprietary software tool for project management designed to assist project managers in developing a plan, assigning resources to tasks, tracking progress, managing a budget, and analyzing workloads. In this sense, it is a useful program for project management in general because it includes a wide range of such utilities as calendar management, resources cost assignments and monitoring and control of the execution of project tasks. Nevertheless, its utility as an educational tool for Project Management is limited. First, there is no strict analysis of the probabilistic duration of tasks according to the PERT method, although introducing optimistic, pessimistic and most likely durations of tasks is allowed. Nevertheless, these three durations are only used for calculating the average estimated duration of every task, and not for stochastic analysis. Therefore, it is not possible to calculate the probability of finishing the project on a given date. Furthermore, Microsoft Project uses the Activities on Nodes (AON) graph and only considers total and free floats and not independent float. Primavera P6 is a professional software package for multi-project planning and control that can be used alone or in combination with other tools. The software is designed specifically for organizations that must simultaneously manage multiple projects and supports multi-user access and an unlimited number of projects. This software uses the CPM technique for project scheduling and resource leveling. The accomplishment of Primavera P6 is similar to that of Microsoft Project, although its large number of options makes it more complicated to use as an educational tool than MS Project. Trautmann \& Baumann [11] proved that the solutions found by Primavera were superior to those of Microsoft Project with the necessity of investigating a large variety of priority rules. Choosing one software is not an easy task. An individual or a company might analyze all aspects and implications, both the negatives and the positives. It is important to focus on the smallest details, as well as on the software's and its costs. As shown in Fig. 4, the courses' costs of Primavera P6 are similar to that of MS Project, although its software and licence's aquisition have a huge difference investment amount required (Figure 4). The budget has been put into dimension and accompanying the trends of modern management theories, everything that is being developed in the world in general. There are some budget methods, the Zero-Based Budget (OBZ) and the Matrix Budget. Zero based budgeting (OBZ) is a budget forecasting methodology that projects revenues, costs and expenses without considering what happened in previous years. It was developed in the US by Texas Instruments Inc. in the 1960s. Its main characteristics include budget analysis of revenues, review of all expenses of the organization, and the level of fixed cost already existing, knowing which are considered to be fixed and all expenses 
that do not vary in relation to the volume sold or manufactured. The benefits of using the Base Zero Budget (OBZ) methodology are many, such as: monthly and annual expenditure monitoring; evaluation of suppliers with their schedules; identification of the real need for resources; evaluation of eminent business threats, with regard to substitute products and merchandise restrictions; changes in the market inherent to the behavior of the demand; better evaluation of the product mix; management by competence of the sales force; need for he-adcount; and real manufacturing capacity among others [12]. To use this procedure the organization must be based on the cost and how much the company has to invest. The reality is that you have to work with what the company produces and has, at first it can be a difficult situation, but with well-executed planning there are several ways to do it. The budget or matrix analysis is a managerial method of management planning and control that has been gaining more and more supporters, mainly due to the ease of elaboration and the cross-objective view provided in the analysis [13]. The matrix model forces each to think strategically about how expenditures will be made and assess whether there are ways to improve the resource requirements that would otherwise be replicated for each area. The matrix budget includes a number of qualitative advantages for the company, including: detailed knowledge of the costs; evaluate the individual performance of each area; besides setting fair and challenging goals; improving the quality of the database for decision-making; schedule continuous changes and improvements in the resource management process; prepare the cost budget to ensure the achievement of an annual expense reduction guideline [13].

They all have many advantages and disadvantages, but the important thing is that the person responsible for the work should choose a better way for the goal to be absolute. The importance of planning and control is enormous within an organization, so a good budget choice is indispensable, the most common one is to use budget analysis and expenditure control, but your concepts fit perfectly in most areas of planning and budgeting, the matrix is initiated with the elaboration of packages of expenses and revenues of companies' businesses. The Base Zero budget is based on the elaboration of a budget base for a given period, without taking into account the previous budgets, then one sees a great advantage. The traditional budget is much more risky due to wastage and lack of planning within a well-structured project, so being aware of all types of budget helps in building and setting goals. There is nothing better than to dedicate yourself to something that in the end shows and proves your excellence, so when making a predetermined choice for what causes you to give your best within the area worked. Therefore, faced with this positive scenario of defense of the Zero-Base Budget by many researchers, there is no way of not considering OBZ as an alternative that should be considered by companies for their budget control as one of the best methods for growth and a good development of a project. Whatever the decision of the company, it is best to choose the budget that best suits your growth and development benefits, so studying and getting to know each one is essential [14-23].

\section{Conclusion}

While the local AEC industry is on its way to establishing BIM processes, PPCP attracts the attention for highlighting the best Brazilian planning tool. It attempts to satisfy predetermined deadlines while operating with the lowest waste level possible during manufacture. PPCP techniques support the entire production line to thrive higher production quality. PPCP focus on aimed objectives to guarantee they will be not only attended but excelled.

\section{Acknowledgement}

None.

\section{Conflict of Interest}

No conflict of interest.

\section{References}

1. Koskela L (1992) Application of the new production philosophy in Construction (CIFE Technical Report, No. 72). Salford: Center for IntegratedFacilityEngineering, USA

2. Chiavenato (2004) Idalberto. Planejamento e Controle da Produção.

3. Mendes R Jr (1999) Programação da produção na construção de edifícios de múltiplos pavimentos (Tese de doutorado). Departamento de Engenharia de Produção e Sistemas, Universidade Federal de Santa Catarina, Florianópolis.

4. Fayol, Rocha CC (2000) Gestão estratégica de custos. In: Construção mercado. São Paulo: Pini, n. 3, p.50-53.

5. DIAS, José Maria AM (2004) Planejamento Organizacional: conceitos e tendências. In: Vasconcellos Filho, Paulo de.

6. Fernandes, Marcos Antônio da Cunha Dias, Jose Maria AM (1982) Planejamento empresarial: teoria \& prática: textos selecionados. Rio de Janeiro: Livros Técnicos e Científicos.

7. Kotler Philip (1999) Administração de marketing: análise, planejamento, implementação e controle. São Paulo: Editora Atlas, Brazil.

8. Formoso TC (2001) Planejamento e controle da produção em empresas de construção. Porto Alegre: Universidade Federal do Rio Grande do Sul.

9. Limmer CV (1997). Planejamento, orçamentação e controle de projetos e obras. Rio de Janeiro: LTC.

10. Coelho HO (1998) Diretrizes e requisitos para o planejamento e controle da produção em nível de médio prazo na construção civil (Dissertação de mestrado). Programa de Pós-graduação em Engenharia Civil, Universidade Federal do Rio Grande do Sul, Porto Alegre, Brazil.

11. Instituto bramante

12. PHYRR (1981) Peter A Orçamento Base Zero - Um instrumentoadministrativo prático para avaliação das despesas, São Paulo- Editora Interciência.

13. Marchesan PRC (2001) Modelo integrado de gestão de custos e controle da produção para obras civis. 163f. Dissertação (Mestrado em Engenharia Civil) - Universidade Federal do Rio Grande do Sul. Porto Alegre, Brazil.

14. Oracle Primavera

15. Primavera

16. Project Professional Online

17. https://www.microsoft.com/pt-br/p/project-onlineprofessional/ cfq7ttc0k8v1?activetab=pivot\%3aoverviewtab, acess in 05/04/2019

18. https://www.trainning.com.br/cursos/curso-pmi-gerenciamentoprojetos-primavera-p6-oracle, acess in 05/03/2019 
19. https://www.trainning.com.br/cursos/curso-pmi-pmp-ms-projectgestao-projetos , acess in 05/03/2019

20. https://www.udemy.com/microsoft-project-the-full-course/, acess in 05/03/2019

21. https://www.udemy.com/primavera-p6-professional-beginner-toexpert/, acess in 05/03/2019
22. https://www.ukconstructionmedia.co.uk/features/bim-progressadoption-uk/, acess in 05/05/2019

23. www.pmkb.com.br/produto/curso-planejando-com-oracle-primaverap6-basico/, acess in 05/03/2019 